\title{
Effects of Mediterranean diet supplemented with lean pork on blood pressure and markers of cardiovascular risk: findings from the MedPork trial
}

\author{
Alexandra T. Wade ${ }^{1}$, Courtney R. Davis ${ }^{1}$, Kathryn A. Dyer ${ }^{1}$, Jonathan M. Hodgson ${ }^{2,3}$, Richard J. Woodman ${ }^{4}$ \\ and Karen J. Murphy ${ }^{1,5 *}$ \\ ${ }^{1}$ Alliance for Research in Exercise, Nutrition and Activity, School of Health Sciences, University of South Australia, GPO Box \\ 2471, Adelaide, SA 5001, Australia \\ ${ }^{2}$ School of Medical and Health Sciences, Edith Cowan University, Perth, WA 6000, Australia \\ ${ }^{3}$ Medical School, University of Western Australia, 35 Stirling Highway, Perth, WA 6000, Australia \\ ${ }^{4}$ Flinders Centre for Epidemiology and Biostatistics, Flinders University, GPO Box 2100 Adelaide, SA 5001, Australia \\ ${ }^{5}$ School of Pharmacy and Medical Sciences, University of South Australia, GPO Box 2471, Adelaide, SA 5001, Australia \\ (Submitted 11 December 2018 - Final revision received 1 April 2019 - Accepted 15 April 2019 - First published online 23 September 2019)
}

\section{Abstract}

The Mediterranean diet offers a range of health benefits. However, previous studies indicate that the restricted consumption of red meat in the diet may affect long-term sustainability in non-Mediterranean countries. A 24-week randomised controlled parallel cross-over design compared a Mediterranean diet supplemented with 2-3 serves per week of fresh, lean pork (MedPork) with a low-fat control diet (LF). Thirty-three participants at risk of CVD followed each intervention for 8 weeks, with an 8 -week washout period separating interventions. The primary outcome was home-measured systolic blood pressure. Secondary outcomes included diastolic blood pressure, fasting lipids, glucose, insulin, C-reactive protein (CRP), body composition and dietary adherence. During the MedPork intervention, participants achieved high adherence to dietary guidelines. Compared with the MedPork intervention, the LF intervention led to greater reductions in weight $(\Delta=-0 \cdot 65 ; 95 \% \mathrm{CI}$ $-0.04,-1.25 \mathrm{~kg}, P=0.04)$, BMI $\left(\Delta=-0.25 ; 95 \% \mathrm{CI}-0.03,-0.47 \mathrm{~kg} / \mathrm{m}^{2}, P=0.01\right)$ and waist circumference $(\Delta=-1.40 ; 95 \% \mathrm{CI}-0.45$, $-2.34 \mathrm{~cm}, P<0 \cdot 01)$. No significant differences were observed for blood pressure, lipids, glucose, insulin or CRP. These findings indicate that Australians are capable of adhering to a Mediterranean diet with 2-3 weekly serves of fresh, lean pork. Larger intervention studies are now required to demonstrate clinical efficacy of the diet in populations with elevated blood pressure.

Key words: Mediterranean diet: CVD: Cardiovascular health: Blood pressure: Pork

The Mediterranean diet is characterised by the high consumption of extra virgin olive oil (EVOO), vegetables, fruits, grains, legumes and nuts; moderate consumption of fish, poultry, eggs, dairy products and red wine; and low consumption of red meat and commercial sweets ${ }^{(1)}$. The components of the Mediterranean diet are rich in bioactive nutrients, including MUFA and PUFA, $n-3$ fatty acids, polyphenols, flavonoids, antioxidants, fibre, and a range of vitamins and minerals.

Cross-sectional and longitudinal studies show that populations following a Mediterranean diet experience better cardiovascular health and lower rates of $\mathrm{CVD}^{(2)}$. Randomised controlled trials corroborate observational findings, reporting improvements to blood pressure, blood vessel function, lipid profiles, atherosclerosis, insulin sensitivity and risk of CVD following adherence to a Mediterranean $\operatorname{diet}^{(3,4-6)}$.
Dietary guidelines in the USA have been revised to include the Mediterranean diet as a healthy dietary pattern while Nutrition Australia have revised their Healthy Eating Pyramid to reflect Mediterranean dietary principles ${ }^{(7)}$. However, few studies have examined the feasibility of implementing a Mediterranean diet in non-Mediterranean populations. Conducted in an older Australian population, the Mediterranean diet for cognitive and cardiovascular health in the elderly (MedLey) study examined cardiovascular and cognitive effects of a Mediterranean diet, as well as dietary adherence and compliance over 6 months. Participants achieved a high level of Mediterranean diet adherence, as measured by a priori adherence scores ${ }^{(8)}$. However, participants also reported that adhering to the red meat restrictions was one of the most challenging aspects of following the $\operatorname{diet}^{(9)}$.

Abbreviations: DBP, diastolic blood pressure; EVOO, extra virgin olive oil; LF, low-fat; MDS, Mediterranean diet score; MedPork, Mediterranean diet supplemented with pork; PREDIMED, Prevención con Dieta Mediterrànea; SBP, systolic blood pressure. 
Mediterranean dietary guidelines recommend consuming $<2$ serves of red meat per week ${ }^{(10,11)}$. A traditional Mediterranean diet includes $105 \mathrm{~g}$, or 0.5-0.75 standard serves of meat and meat products per $\mathrm{d}^{(1)}$. This figure is inclusive of all processed and unprocessed red and white meat products. In contrast, Australians over the age of 19 years consume an average of $184 \mathrm{~g}$ of meat per $\mathrm{d}$, or 1.7 serves of lean meats and alternates, with red meat contributing the largest proportion of this $(38 \%)^{(12)}$. Australians are amongst the highest consumers of meat in the world ${ }^{(13)}$. Therefore, restricting red meat may be difficult. Countries with comparatively high meat intakes, such as the USA and UK, may experience similar challenges ${ }^{(13)}$. As socio-cultural norms and palatability are key determinants of a dietary intervention's sustainability $^{(14)}$, non-Mediterranean populations may be more likely to adhere to a diet containing more red meat or meat protein.

Prospective studies indicate that red meat consumption may be linked to poorer health outcomes, including bowel cancer and $\mathrm{CVD}^{(15)}$. However, recent investigations suggest that the presence of other dietary components, including oleic acid, vitamin $\mathrm{E}$ and fibre, may attenuate the negative effects of red meat consumption $^{(16,17,18)}$.

In Australia, beef, veal and pork are the most frequently consumed red meats ${ }^{(13)}$. Fresh lean beef and fresh lean pork have similar nutrient profiles. However fresh lean pork contains less saturated fat per $100 \mathrm{~g}$. Therefore, pork may be a suitable addition to the Mediterranean diet, which is typically low in saturated fat and haeme Fe sources ${ }^{(1)}$. Substituting beef and chicken with pork also positively affects weight, BMI, percentage body fat, fat mass and abdominal fat ${ }^{(19)}$. Further, when compared with ruminant meats such as beef, pork production is associated with significantly less agricultural greenhouse gas emissions ${ }^{(20)}$.

To our knowledge, no studies have investigated the cardiovascular effects of a Mediterranean diet with an increased intake of lean red meat. Therefore, the present study aimed to evaluate the cardiovascular effects of a Mediterranean diet supplemented with fresh lean pork against a low-fat (LF) diet. An LF control diet was chosen due to its continued recommendation for the clinical management and reduction of cardiovascular risk ${ }^{(21)}$. Further, including an LF control would enable comparisons of our findings with larger studies of the same design, such as the Prevención con Dieta Mediterránea (PREDIMED) trial ${ }^{(22)}$.

\section{Methodology}

The study protocol has been described in detail elsewhere ${ }^{(23)}$.

\section{Ethics and registration}

This trial was registered with the Australian New Zealand Clinical Trials Registry (ACTRN12616001046493) on August 2016 and was conducted in accordance with the Declaration of Helsinki. All procedures involving human participants were approved by the University of South Australia Human Ethics Committee (no. 35662).

\section{Participants and recruitment}

Volunteers aged between 45 and 80 years and at risk of developing CVD were recruited between January and May 2017 via electronic and paper advertisements.
Volunteers were required to have systolic blood pressure (SBP) above $120 \mathrm{mmHg}$ and at least two other risk factors for CVD, including a BMI $\geq 25 \mathrm{~kg} / \mathrm{m}^{2}$; elevated fasting total cholesterol $(\geq 5.5 \mathrm{mmol} / \mathrm{l})$, TAG $(\geq 2.0 \mathrm{mmol} / \mathrm{l})$, LDL $(\geq 3.5 \mathrm{mmol} / \mathrm{l})$ or low levels of HDL $(\leq 0.9 \mathrm{mmol} / 1$ for men and $\leq 1.0 \mathrm{mmol} / \mathrm{l}$ for women); impaired fasting glucose tolerance (between $6 \cdot 1$ and $7.8 \mathrm{mmol} / \mathrm{l}$ ); and/or a family history (up to one generation) of CVD or type 2 diabetes mellitus. Exclusion criteria included antihypertensive medication; smoking; current CVD or angina; current or recent (within 6 months) malignancies; respiratory disease; gastrointestinal disease; kidney disease; a current diagnosis of type 2 diabetes mellitus; a current or previous traumatic head or brain injury; a current neurological or psychiatric condition; antidepressant or anxiety medication; a current diagnosis of Alzheimer's disease or dementia; high adherence to a Mediterranean diet indicated by a score of 10 or more, out of a total possible fifteen points, assessed using a modified Mediterranean diet adherence survey (described below); or supplemental $n$-3 fatty acids $>1000 \mathrm{mg}$ daily.

\section{Design}

A 24-week parallel cross-over design trial compared a Mediterranean diet intervention with 2-3 weekly serves of pork (MedPork) with an LF control intervention. Each participant completed both dietary interventions for 8 weeks and the two intervention phases were separated by an 8 -week washout period (see Fig. 1). Using block randomisation and a block size of 4 , an independent staff member randomly assigned participants to their first dietary intervention (MedPork or LF), stratified by sex and age. During the washout period, participants returned to their habitual diet. An 8-week intervention period was deemed adequate due to previous research, which indicates that the nutrients contained within the Mediterranean diet can improve both cardiovascular function over similar time periods ${ }^{(24-26)}$.

\section{Dietary interventions}

Neither diet restricted energy intake. Participants were advised to consume foods ad libitum and self-regulate their food intake according to individual hunger and satiety cues.

Low-fat diet. Guidelines for the LF diet were based on the PREDIMED study ${ }^{(27)}$. General guidelines were adapted from the Australian Guide to Healthy Eating and the National Heart Foundation Guidelines $(2012)^{(28,29)}$. Participants were advised to make adjustments to their habitual diet in order to reduce total fat intake. For example, participants were recommended to replace high-fat foods, including all types of oil, butter, margarine, processed and high-fat meats, nuts, chocolates, cakes, pastry, and high- or full-fat dairy products, with LF alternatives, such as breads and cereals, legumes, rice, fruits and vegetables and LF varieties (e.g. LF dairy products, LF sauces). Daily limits were set for oil ( $\leq 20 \mathrm{ml}$ ), butter and margarine ( $\leq 2$ teaspoons), and participants were instructed to remove visible fat and skin from meat and fish before cooking.

Mediterranean diet supplemented with pork. Guidelines for the MedPork intervention were adapted from Estruch et al. ${ }^{(22)}$ 


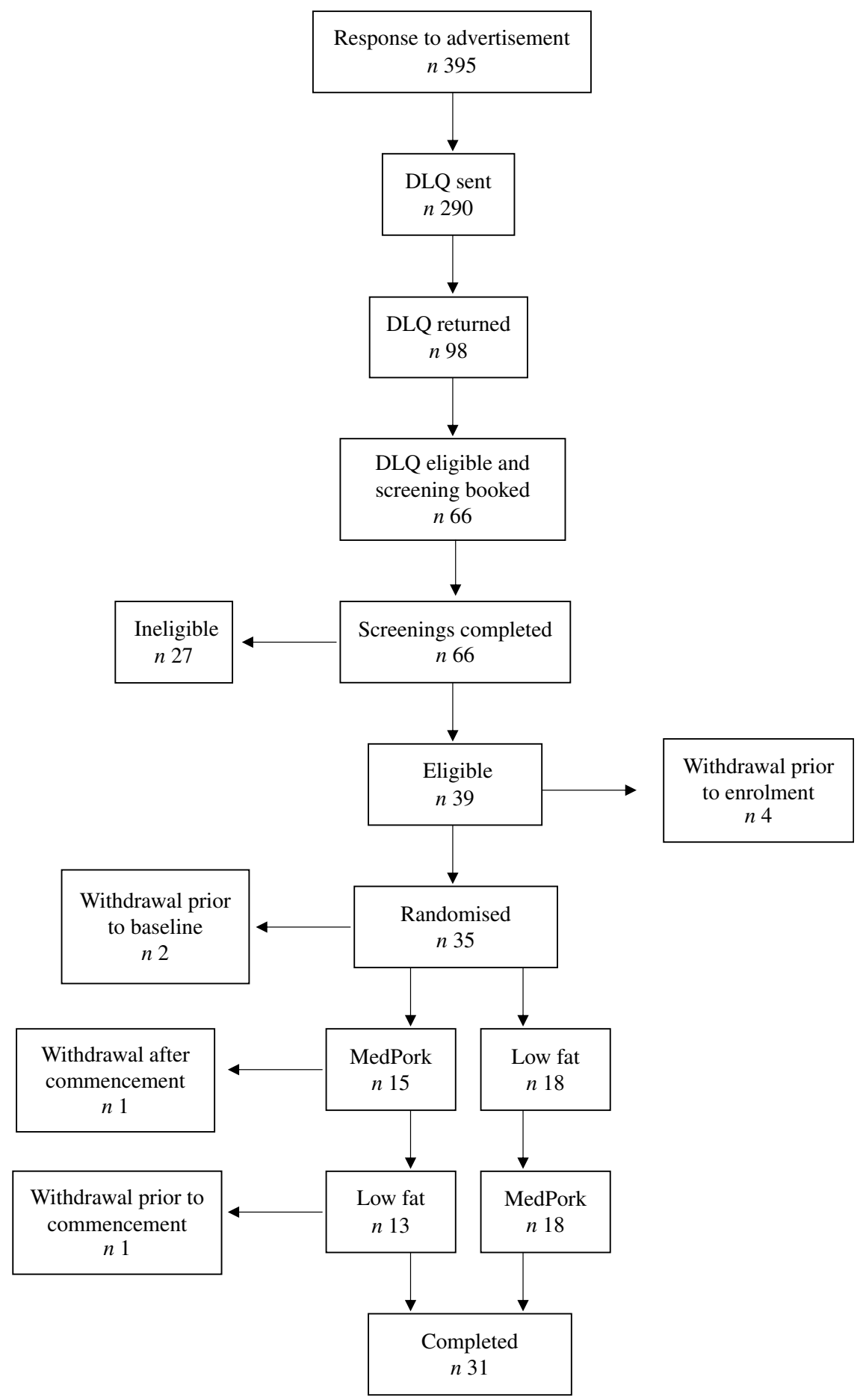

Fig. 1. Consolidated Standards of Reporting Trials (CONSORT) diagram illustrating flow of participants from recruitment through to study completion. Intention-to-treat analysis is based on all participants with baseline data $(n 33)$. DLQ, Diet and Lifestyle Questionnaire; MedPork, Mediterranean diet supplemented with pork.

for an Australian food supply and to include increased serves of fresh lean pork:

- $\quad$ Minimum of one tablespoon (20 ml) of EVOO per d;

- $\quad \geq 2-3$ daily servings of fresh fruit (1 serve $=150 \mathrm{~g}$ fresh, $30 \mathrm{~g}$ dried, or one cup canned in natural juice);

- $\quad \geq 3$ weekly servings of legumes (1 serve = $75 \mathrm{~g}$ );
- $\quad 2-3$ weekly servings of fresh lean pork (1 serve $=100 \mathrm{~g}$ cooked)

- $\quad \geq 3$ weekly servings of fish and seafood (at least 1 serving of oily fish) ( 1 serve $=100 \mathrm{~g}$ cooked);

- $\quad \geq 5$ weekly serving of raw or roasted nuts or seeds, without added salt, sugar or chocolate (1 serve $=30 \mathrm{~g}$; 
$7.5 \mathrm{~g}$ hazelnuts, $15 \mathrm{~g}$ walnuts, $7.5 \mathrm{~g}$ almonds supplied for each serve);

- Ad libitum consumption of wholegrain cereal products (bread, pasta, rice, cereal) and dairy products;

- Ad libitum consumption of eggs, not to exceed 6 serves per week (1 serve = approximately $70 \mathrm{~g}$ or $1 \mathrm{egg}$ );

- $\quad$ Select white meats (poultry without skin) instead of red meats or processed meats;

- Limit consumption of red and cured meat (remove all visible fat) to $\leq 1$ serve/week ( 1 serve of red meat/cured ham $=100 \mathrm{~g}$ );

- Limit consumption of chocolate to $\leq 1$ serve/week ( 1 serve of chocolate $=50 \mathrm{~g}$ );

- Use EVOO for cooking and dressing vegetables and salad;

- Cook regularly (at least twice a week) with a tomatobased sauce (EVOO, tomato, garlic and onion);

- Dress vegetables, pasta, rice and other dishes with EVOO, tomato, garlic and onion sauce;

- Eliminate or limit the consumption of cream, butter, margarine, cold meat, pâté, duck, carbonated and/or sugared beverages, pastries, commercial bakery products (cakes, doughnuts, cookies), desserts (puddings), French fries, potato crisps, sweets; and

- For usual drinkers, red wine is recommended as the main source of alcohol with a maximum of two standard drinks per $\mathrm{d}\left(200 \mathrm{ml}=\right.$ two standard drinks). ${ }^{(30)}$

Participants were advised to consume pork in place of chicken and red meat and ensure that total meat consumption did not exceed $400 \mathrm{~g}$ (four serves) per week.

Notably, recommendations for EVOO differ from the original PREDIMED guidelines, which advised participants to consume $\geq 60 \mathrm{ml} / \mathrm{d}$. This decision was made to increase acceptability for an Australian population, where EVOO is consumed neither habitually nor in abundance ${ }^{(8)}$. Although considerably lower than recommendations from the PREDIMED trial, previous research conducted in Australia has indicated that a Mediterranean diet containing $\geq 1$ tablespoon of EVOO per $\mathrm{d}$ is capable of improving cardiovascular outcomes ${ }^{(4)}$.

To assist with adherence, the following foods were provided each week: $375 \mathrm{ml}$ EVOO (donated by Cobram Estate); $250 \mathrm{~g}$ of fresh lean pork; $150 \mathrm{~g}$ raw, unsalted almonds (donated by Almond Board of Australia), walnuts and hazelnuts; $225 \mathrm{~g}$ (net weight) of canned chickpeas, red kidney beans, four-bean mix and lentils (donated by Simplot Australia Pty Ltd); $95 \mathrm{~g}$ of canned tuna; and $95 \mathrm{~g}$ of canned salmon (donated by Simplot Australia Pty Ltd).

Dietetic counselling. For the Mediterranean diet and LF diets, participants were provided with a set of dietary resources as described by Wade et al. ${ }^{(23)}$. Throughout each intervention phase, participants attended fortnightly dietetic visits to discuss progress, food intake, challenges and any adverse effects. Dietetic visits also included weight measurement to determine body mass, weight loss or weight gain.

\section{Outcome measures}

Home blood pressure. Home-measured SBP was the primary outcome measure. Participants received training on self- administered blood pressure measurement and were provided with a clinically validated A\&D Company Ltd digital blood pressure monitor (model UA-767). Participants were instructed to take three blood pressure measurements, with a 1-min rest period in between each reading, every morning, afternoon and evening for a period of $6 \mathrm{~d}$.

Secondary outcome measures. Over the four assessment time points, home-measured diastolic blood pressure (DBP) and heart rate, clinic blood pressure and heart rate, BMI, waist:hip ratio, body composition, fasting blood lipids, C-reactive protein, fasting plasma glucose, fasting serum insulin, dietary adherence and nutrient intake were secondary outcomes.

Dietary adherence. A fiteen-item MedPork adherence survey and a nine-item LF diet adherence survey were administered to participants fortnightly to capture generalised patterns of food consumption during each of the intervention phases. Surveys were adapted from the Mediterranean diet and LF questionnaires used in the PREDIMED study ${ }^{(27)}$. The scoring of the Mediterranean diet survey was modified to reflect our MedPork guidelines developed for an Australian population as outlined above. Specifically, consumption of $\geq 1$ tablespoon of EVOO was awarded 1 point in the present study, as compared with the necessary $\geq 4$ tablespoons in the PREDIMED design. An item relating to fresh pork consumption was also included to reflect the MedPork intervention. See Supplementary material S1 for surveys and scoring. During the MedPork intervention, participants also completed a semi-quantitative weekly checklist (described above). In line with the study protocol, participants required to achieve a minimum of $75 \%$ adherence on the MedPork and LF surveys each fortnight.

Adherence to the Mediterranean diet was also calculated using the Mediterranean diet score (MDS), developed by Trichopoulou et al. ${ }^{(31)}$. The MDS was applied to dietary data from 3 - $\mathrm{d}$ weighed food records completed by participants before and at the end of each intervention phase.

\section{Procedure}

Participants attended a prebaseline appointment at the Sansom Institute for Health Research Clinical Trial Facility (SIHR CTF) where the study was explained, and informed consent was obtained by study personnel. Instructions and equipment were given for the collection of home measures, including blood pressure and weighed food records. Participants then returned 1 week later for week 0 assessments.

Clinic assessment visits took place at baseline of the first diet (week 0), at the end of the first diet (week 8), at baseline of the second diet, after the 8-week washout period (week 16) and at the end of the second diet (week 24). Data for home measures were collected by participants in the week prior to each of these visits.

Volunteers were instructed to continue any habitual exercise and medications for the duration of the trial. Changes to exercise and medications were monitored and recorded at fortnightly dietetic visits and clinic assessment visits by the investigators.

\section{Statistical analysis}

Statistical analyses were conducted using SPSS for Windows, version 21.0 (SPSS Inc.) and Stata (version 14.2, StataCorp). 
Weighed food records were entered into Foodworks Professional software (version 9.0, Xyris Software) to calculate food group and nutrient values. Serve sizes are based on recommendations from the Australian Guide to Healthy Eating ${ }^{(28)}$.

Data are presented as means and standard deviations or standard errors for descriptive statistics and as means and 95\% CI for estimated effects. All tests are two-tailed with $P<0.05$ deemed statistically significant. Residuals were screened for normality and variables were transformed if necessary.

Based on power calculations, a sample size of thirty-one volunteers was required to detect a clinically relevant difference of $2.5 \mathrm{mmHg}$ in home blood pressure, the primary outcome measure, with power of $90 \%$. This calculation assumes a total of fifty-four blood pressure readings (three readings taken three times per $\mathrm{d}$ for $6 \mathrm{~d}$ ) at each time point, a withingroup SD of $14 \mathrm{mmHg}$, a within-subject repeated measures correlation of $r 0.6$ and a between-phase within-subject correlation of $\rho=0 \cdot 5$. The correlation $(\rho)$ and use of a cross-over design reduce the number of required participants required for a parallel group design by a factor of $1 /(1-\rho) / 2=4^{(32)}$, that is, from approximately 124 subjects for a parallel group design using ANCOVA with adjustment for baseline ( $n 62$ per group) to thirty-one subjects in total.

Linear mixed-effects models were used to compare the effects of the two treatments. The period of intervention (first $v$. second), the order in which dietary interventions were given (LF first $v$. MedPork first), the visit (baseline $v$. week 8) and an interaction term for treatment $\times$ visit were included in the model as fixed effects, while subjects were included as random effects. Differences in effects between treatments were assessed using the estimated marginal mean differences in week- 8 values between treatments and the associated $P$ values. We also investigated possible period effects and carryover effects using treatment $\times$ visit $\times$ period and visit $\times$ period interaction terms, respectively. Where significant these terms were also included in the model. As change in weight might potentially influence the treatment effects, weight at each time point was included as a covariate for all cardiometabolic outcomes, excluding measures of body composition and adiposity. Intention to treat analyses was performed by including all participants with baseline data ( $n$ 33). Missing data were estimated by relying on the best linear unbiased predictions in each mixed model. Difference in change between interventions (i.e. the difference between week 0 and week 8 following the MedPork intervention $v$. the difference between week 0 and week 8 following the LF intervention) is presented as the 'estimated mean difference between interventions (MedPork $v$. LF)'. Positive values indicate an increase following the MedPork intervention and negative values indicate a decrease following the MedPork intervention. For log-transformed data, the difference between interventions is presented as the rate ratio change in the geometric mean.

Since obesity leads to increaseds blood pressure and a subsequent risk of the metabolic syndrome and $\mathrm{CVD}^{(33)}$, we conducted post hoc sub-group analyses for home-measured blood pressure and cardiometabolic outcomes, grouping participants into overweight (BMI $\geq 25-<30 \mathrm{~kg} / \mathrm{m}^{2} ; n$ 17) and obese (BMI $\geq 30 \mathrm{~kg} / \mathrm{m}^{2} ; n$ 14) categories. Participants with a BMI $<$ $25 \mathrm{~kg} / \mathrm{m}^{2}(n$ 2) were excluded from this analysis.
Table 1. Demographic and clinical characteristics of the study sample at baseline, according to first dietary intervention* (Mean values and standard deviations; numbers and percentages)

\begin{tabular}{|c|c|c|c|c|c|c|}
\hline & \multicolumn{2}{|c|}{ Total $(n 33)$} & \multicolumn{2}{|c|}{$\begin{array}{c}\text { Group } 1 \\
(n 15)\end{array}$} & \multicolumn{2}{|c|}{$\begin{array}{c}\text { Group } 2 \\
(n 18)\end{array}$} \\
\hline & Mean & SD & Mean & SD & Mean & SD \\
\hline Age (years) & $61 \cdot 0$ & $7 \cdot 1$ & $60 \cdot 2$ & $8 \cdot 7$ & 61.6 & $5 \cdot 7$ \\
\hline \multicolumn{7}{|l|}{ Sex } \\
\hline \multicolumn{7}{|l|}{ Males } \\
\hline$n$ & \multicolumn{2}{|c|}{10} & \multicolumn{2}{|c|}{6} & \multicolumn{2}{|c|}{4} \\
\hline$\%$ & \multirow{2}{*}{\multicolumn{2}{|c|}{$30 \cdot 3$}} & \multirow{2}{*}{\multicolumn{2}{|c|}{$40 \cdot 0$}} & \multicolumn{2}{|c|}{$22 \cdot 2$} \\
\hline \multicolumn{4}{|l|}{ Females } & & & \\
\hline$n$ & \multirow{2}{*}{\multicolumn{2}{|c|}{$\begin{array}{c}23 \\
69 \cdot 7\end{array}$}} & \multirow{2}{*}{\multicolumn{2}{|c|}{$\begin{array}{c}9 \\
60.0\end{array}$}} & \multicolumn{2}{|c|}{14} \\
\hline$\%$ & & & & & 77 & \\
\hline Education (years) & $16 \cdot 7$ & 4.4 & $15 \cdot 7$ & 3.5 & 17.5 & 4.9 \\
\hline Home SBP average $(\mathrm{mmHg})$ & $128 \cdot 9$ & $12 \cdot 1$ & $129 \cdot 2$ & $14 \cdot 0$ & $128 \cdot 5$ & $10 \cdot 4$ \\
\hline Home DBP average $(\mathrm{mmHg})$ & $76 \cdot 1$ & 8.5 & 74.7 & 9.0 & 77.4 & $8 \cdot 1$ \\
\hline Home HR average (bpm) & $71 \cdot 0$ & $7 \cdot 0$ & 71.9 & $7 \cdot 8$ & $70 \cdot 1$ & $6 \cdot 2$ \\
\hline Insulin (mU/I) & $10 \cdot 7$ & $5 \cdot 2$ & $10 \cdot 0$ & 4.5 & $11 \cdot 2$ & $5 \cdot 7$ \\
\hline Glucose $(\mathrm{mmol} / \mathrm{l})$ & 5.4 & 0.6 & $5 \cdot 3$ & 0.6 & $5 \cdot 4$ & 0.6 \\
\hline Total cholesterol (mmol/l) & $5 \cdot 8$ & 0.9 & 5.9 & 0.8 & $5 \cdot 6$ & 1.0 \\
\hline Weight (kg) & $85 \cdot 1$ & $17 \cdot 7$ & 87.8 & $17 \cdot 3$ & $82 \cdot 7$ & $18 \cdot 2$ \\
\hline BMI $\left(\mathrm{kg} / \mathrm{m}^{2}\right)$ & $30 \cdot 6$ & $5 \cdot 1$ & $31 \cdot 6$ & $5 \cdot 7$ & 29.8 & 4.6 \\
\hline
\end{tabular}

SBP, systolic blood pressure; DBP, diastolic blood pressure; HR, heart rate; bpm, beats per min; MedPork, Mediterranean diet supplemented with pork. * Group 1 received the MedPork intervention first; group 2 received the low-fat intervention first.

Previous studies have indicated that blood pressure readings taken on the first day of home blood pressure measurement may be higher than subsequent days. Daily averages were computed for each of the $6 \mathrm{~d}$ of home-measured SBP at week 0 (baseline) for each period. Paired samples $t$ tests were conducted to compare day 1 with all other days. No significant differences were detected at $P<0.05$ and therefore day 1 of SBP readings were retained in the analysis. Averages were also computed for the first, second and third readings of each day at week 0 . Paired sampled $t$ tests revealed significant differences for first readings as compared with second and third readings. The first reading for each day was therefore excluded from the analysis.

\section{Results}

A total of thirty-five participants were randomised. Baseline data were collected for thirty-three participants, who formed the modified intention-to-treat population. A total of thirty-one participants completed the two dietary interventions.

Results are based on the modified intention to treat population ( $n$ 33). Participants were randomly allocated to their starting dietary intervention. Group 1 ( $n$ 15) completed the MedPork intervention in period 1 and the LF intervention in period 2; group 2 ( $n$ 18) completed the LF intervention in period 1 and the MedPork intervention in period 2. Baseline characteristics of each group are presented in Table 1. No significant differences were detected between groups for demographic or cardiometabolic outcomes.

Fig. 1 illustrates the consort flow of the study, indicating time of withdrawals. Of the thirty-three subjects, one participant withdrew during the MedPork intervention in the first period and one participant withdrew during the washout period, prior to 


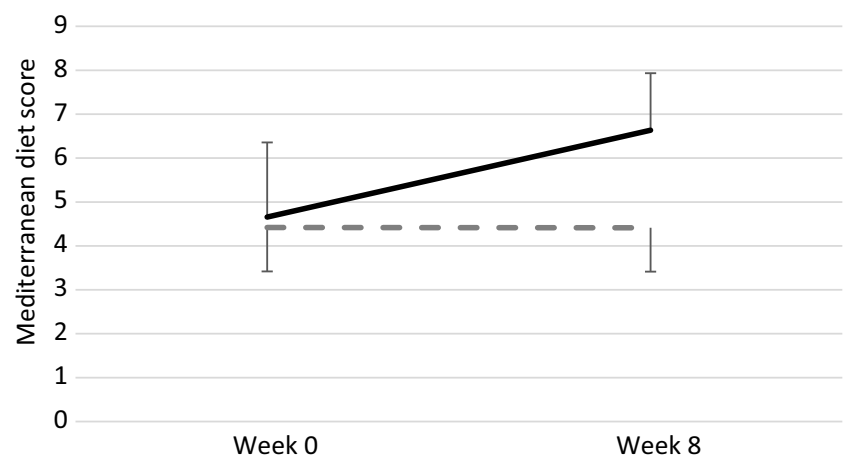

Fig. 2. Adherence to the Mediterranean diet before and during the MedPork ( - ) and low-fat (LF; - -) interventions, according to the Mediterranean diet score developed by Trichopoulou et al.(31). Mediterranean diet adherence increased from 4.7 to 6.6 by the end of the MedPork intervention and remained at 4.4 throughout the LF intervention. Data are means, with standard deviations represented by vertical bars.

commencing the LF intervention. Reasons for withdrawal included competing commitments ( $n 1$ ) and illness preventing adherence to dietary intervention $(n 1)$.

\section{Period and carryover effects}

A period effect for treatment (significant treatment $\times$ visit $\times$ period interaction) was detected for home-measured morning DBP, total cholesterol and HDL. Possible carryover effects (significant visit $\times$ period interaction) were detected for clinic DBP and LDL.

\section{Dietary adherence and nutrient intake}

Throughout both dietary interventions, all participants met the minimum requirement of $75 \%$ dietary adherence. No participants were excluded from the study for failure to meet MedPork dietary guidelines.

The average LF adherence score achieved across the four fortnights of the LF intervention was $8.4 \pm 1 \cdot 1$ out of a maximum of 9 points ( $93.3 \%$ compliance).

The average MedPork adherence score during the MedPork intervention was $13.5 \pm 1.7$ out of 15 (90\% compliance), representing an increase of 7.5 points from screening. According to the Trichopoulou et al. MDS ${ }^{(31)}$ mean Mediterranean diet adherence increased from 4.7 (SD 1.8) to 6.6 (SD 1.3) out of 9 during the MedPork intervention and remained at 4.4 (SD 1.7) during the LF intervention (Fig. 2).

Nutrient and food group intakes across both intervention periods are presented in Table 2. According to weighed food records and fortnightly checklists, mean fresh pork intake increased from 0.09 (SE 0.1) serves per d to 0.44 (SE 0.1) serves per d (approximately 3 serves per week) during the MedPork intervention and decreased from $0 \cdot 16(\operatorname{se} 0 \cdot 3)$ serves per $d$ to $0 \cdot 13$ (sE $0 \cdot 2)$ serves per d during the LF intervention $(P \leq 0 \cdot 001)$ (Table 2$)$.

After 8 weeks, compared with the LF intervention, the MedPork intervention led to a significantly higher intake of \% energy from fat $(P<0.001)$, \% energy from MUFA $(P<0.001)$, \% energy from PUFA $(P<0.001)$ and MUFA:SFA $(P<0 \cdot 001)$. The LF intervention led to significantly higher intake of $\%$ energy from protein $(P<0.01)$ and carbohydrates $(P<0.001)$. The MedPork intervention led to significantly lower consumption of refined grains $(P<0.01)$, and higher consumption of legumes $(P<0 \cdot 01)$, seafood $(P<0.01)$, nuts and seeds $(P<0.001)$, EVOO $(P<0 \cdot 001)$, meat and meat alternatives $(P<0.001)$, but not red meat $(P=0.27)$.

The MedPork intervention led to significantly higher consumption of vitamin $\mathrm{E}(P<0.001)$, linoleic acid $(P<0.001)$ and $\alpha$-linolenic acid $(P<0 \cdot 001)$. The LF intervention led to significantly higher intake of total folate $(P \leq 0 \cdot 01)$. No other significant differences were observed across nutrients.

\section{Home-measured blood pressure}

Results for home-measured blood pressure are presented in Table 3. For participants who completed blood pressure measurements at all time points ( $n 31$ ), an average of $49 / 54$ measures were taken, indicating $90 \%$ compliance with instruction.

There was no difference in the changes to home SBP or DBP between the MedPork and LF diets for morning, afternoon, evening and average blood pressure $(\mathrm{mmHg})$ or heart rate (beats per min) measurements. Similar trends were observed for SBP ( $\mathrm{mmHg}$ ) for both the MedPork and LF intervention, where morning, afternoon and average blood pressure decreased between baseline and week 8 .

\section{Secondary outcomes}

Results for secondary cardiometabolic outcomes are presented in Table 4. The LF intervention led to significantly greater reductions in weight $(\mathrm{kg})(P=0 \cdot 04)$, BMI $\left(\mathrm{kg} / \mathrm{m}^{2}\right)(P=0 \cdot 01)$, waist circumference $(\mathrm{cm})(P \leq 0.01)$ and fat mass $(\mathrm{kg})(P=0.04)$ compared with MedPork. No significant differences between diets were observed for clinic measures of SBP, DBP $(\mathrm{mmHg})$ or heart rate (beats per min), insulin, glucose, C-reactive protein, total cholesterol, total TAG, HDL, LDL (mmol/l) or total cholesterol:HDL.

\section{Sub-group analyses}

Sub-group analyses are presented in Table 5. In the overweight group, average home SBP ( $\mathrm{mmHg}$ ) was reduced more in the MedPork intervention compared with the LF intervention $(P=0.01)$. In contrast, in the obese group, average home SBP $(\mathrm{mmHg})$ was reduced more in the LF intervention compared with the MedPork intervention $(P<0 \cdot 001)$.

The MedPork intervention increased average home DBP (mmHg) more than the LF intervention in the overweight group $(P<0.01)$. There was no difference between interventions for average home DBP in the obese group.

Consistent with the changes in home SBP and home DBP, the MedPork led to a greater reduction in pulse pressure in the overweight group $(P \leq 0 \cdot 01)$, while the LF intervention led to a greater reduction in pulse pressure $(\mathrm{mmHg})$ in the obese group $(P \leq 0.001)$.

\section{Discussion}

The present study examined the cardiovascular effects of including 2-3 serves per week of fresh lean pork as a part of a 
Table 2. Energy and nutrient intakes at baseline and week 8 , including between-group differences

(Mean values with their standard errors; mean differences and $95 \%$ confidence intervals)

\begin{tabular}{|c|c|c|c|c|c|c|c|c|c|c|c|}
\hline \multirow[b]{3}{*}{ Nutrients } & \multicolumn{4}{|c|}{ MedPork diet (n 33) } & \multicolumn{4}{|c|}{ LF diet ( $n$ 33) } & \multirow{2}{*}{\multicolumn{2}{|c|}{$\begin{array}{c}\text { Estimated difference } \\
\text { between interventions } \\
(\text { MedPork } v . L F)^{*} \dagger\end{array}$}} & \multirow[b]{3}{*}{$P \ddagger$} \\
\hline & \multicolumn{2}{|c|}{ Baseline } & \multicolumn{2}{|c|}{ Week 8} & \multicolumn{2}{|c|}{ Baseline } & \multicolumn{2}{|c|}{ Week 8} & & & \\
\hline & Mean & SE & Mean & SE & Mean & SE & Mean & $\mathrm{SE}$ & Mean & $95 \% \mathrm{Cl}$ & \\
\hline Energy (MJ) & 8.96 & 0.33 & 8.33 & 0.33 & 9.00 & 0.33 & $7 \cdot 86$ & 0.34 & 0.47 & $-0.32,1.27$ & 0.24 \\
\hline$\%$ Energy from protein & 18.40 & 0.65 & 19.71 & 0.67 & $19 \cdot 45$ & 0.66 & $22 \cdot 21$ & 0.68 & $-2 \cdot 51$ & $-4 \cdot 10,0.91$ & $<0.01$ \\
\hline$\%$ Energy from total fat & 34.08 & 1.25 & 36.84 & 0.67 & 34.59 & 1.27 & 27.52 & 1.31 & $9 \cdot 32$ & $5 \cdot 91,12 \cdot 74$ & $<0.001$ \\
\hline$\%$ Energy from SFA & $12 \cdot 07$ & 0.57 & $9 \cdot 18$ & 0.58 & $12 \cdot 24$ & 0.57 & 9.23 & 0.59 & -0.05 & $-1 \cdot 41,1 \cdot 31$ & 0.94 \\
\hline$\%$ Energy from PUFA & 5.41 & 0.34 & $7 \cdot 61$ & 0.35 & 5.53 & 0.35 & 5.05 & 0.36 & 2.56 & $1.61,3.51$ & $<0.001$ \\
\hline$\%$ Energy from MUFA & 13.89 & 0.76 & 17.37 & 0.79 & $14 \cdot 16$ & 0.77 & $10 \cdot 68$ & 0.80 & 6.69 & $4.55,8.83$ & $<0.001$ \\
\hline MUFA:SFA $†$ & 1.24 & 0.09 & 1.99 & 0.09 & $1 \cdot 19$ & 0.09 & $1 \cdot 18$ & 0.09 & 1.69 & $1.46,1.95$ & $<0.001$ \\
\hline$\%$ Energy from carbohydrates & 39.50 & 1.37 & $35 \cdot 23$ & 1.37 & 38.59 & 1.35 & $41 \cdot 23$ & 1.39 & $-6 \cdot 00$ & $-9 \cdot 22,-2 \cdot 79$ & $<0.001$ \\
\hline \% Energy from alcohol & 4.41 & 0.81 & 3.45 & 0.82 & 3.54 & 0.82 & 3.99 & 0.83 & -0.55 & $-1.75,0.65$ & 0.37 \\
\hline Cholesterol (mg/MJ)† & 37.76 & 3.40 & 33.64 & 3.48 & 43.57 & 3.44 & 38.97 & 3.58 & 0.82 & $0.68,1.01$ & 0.06 \\
\hline Fibre (g/MJ) & 3.03 & 0.19 & 3.98 & 0.19 & 3.06 & $0 \cdot 19$ & 3.84 & 0.20 & 0.14 & $-0.31,0.59$ & 0.54 \\
\hline Vit C (mg/MJ)† & 11.34 & 0.39 & 21.53 & 1.56 & 12.53 & 1.51 & $17 \cdot 26$ & 1.58 & 0.81 & $0.96,1.59$ & 0.10 \\
\hline Vit E (mg/MJ)† & 1.64 & 0.11 & $2 \cdot 14$ & 0.12 & 1.47 & $0 \cdot 12$ & 1.40 & 0.12 & 1.57 & $1.33,1.85$ & $<0.001$ \\
\hline Total vit A equiv. $(\mu \mathrm{g} / \mathrm{MJ}) \dagger$ & $112 \cdot 80$ & 12.59 & 133.77 & $12 \cdot 04$ & $119 \cdot 91$ & $12 \cdot 75$ & 123.06 & 13.07 & 0.99 & $0.79,1.25$ & 0.96 \\
\hline Total folate $(\mu \mathrm{g} / \mathrm{MJ})$ & 61.65 & 3.56 & $68 \cdot 28$ & 3.68 & 63.94 & 3.63 & $81 \cdot 11$ & 3.74 & $-12 \cdot 83$ & $-21.57,4.09$ & $<0.01$ \\
\hline$\beta$-Carotene equiv. $(\mu \mathrm{g} / \mathrm{MJ}) \dagger$ & 489.23 & 74.72 & 673.45 & 77.36 & $513 \cdot 14$ & $75 \cdot 66$ & $581 \cdot 35$ & 77.51 & 1.13 & $0.83,1.54$ & 0.45 \\
\hline $\mathrm{Na}(\mathrm{mg} / \mathrm{MJ})$ & 280.09 & $15 \cdot 28$ & 243.15 & $15 \cdot 51$ & $315 \cdot 64$ & $15 \cdot 26$ & 283.93 & $15 \cdot 80$ & -40.78 & $-82 \cdot 36,0.79$ & 0.06 \\
\hline $\mathrm{Ca}(\mathrm{mg} / \mathrm{MJ})$ & $103 \cdot 65$ & 6.53 & $112 \cdot 04$ & 0.75 & $108 \cdot 87$ & $6 \cdot 61$ & $122 \cdot 25$ & $6 \cdot 76$ & $-10 \cdot 21$ & $-23 \cdot 76,3 \cdot 33$ & 0.14 \\
\hline $\mathrm{Fe}(\mathrm{mg} / \mathrm{MJ}) \dagger$ & 1.48 & 0.07 & 1.48 & 0.07 & 1.39 & 0.07 & 1.63 & 0.07 & 0.93 & $0.82,1.05$ & $0 \cdot 21$ \\
\hline Zn (mg/MJ) & 1.32 & 0.06 & 1.27 & 0.06 & 1.30 & 0.06 & 1.40 & 0.06 & -0.12 & $-0.26,0.01$ & 0.07 \\
\hline Linoleic acid (g/MJ) & $1 \cdot 18$ & 0.08 & 1.69 & 0.08 & 1.23 & 0.08 & $1 \cdot 11$ & 0.09 & 0.59 & $0.36,0.81$ & $<0.001$ \\
\hline$\alpha$-Linolenic acid (g/MJ) $\dagger$ & 0.17 & 0.01 & 0.23 & 0.02 & 0.16 & 0.02 & $0 \cdot 16$ & 0.02 & 1.49 & $1.19,1.86$ & $<0.001$ \\
\hline \multicolumn{12}{|l|}{ Serves/d } \\
\hline Wholegrains $\dagger$ & $2 \cdot 14$ & 0.26 & 2.44 & 0.27 & 1.70 & 0.26 & 2.03 & 0.27 & 1.49 & $0.88,2.54$ & 0.14 \\
\hline Refined grains $\dagger$ & 3.61 & 0.37 & 1.96 & 0.38 & 3.84 & 0.38 & 3.45 & 0.38 & 0.65 & $0.49,0.85$ & $<0.01$ \\
\hline Fruits & 1.30 & 0.17 & $2 \cdot 20$ & 0.18 & 1.57 & $0 \cdot 18$ & 1.74 & 0.18 & 0.46 & $0.05,0.86$ & 0.03 \\
\hline Vegetables $\dagger$ & 4.39 & 0.60 & 5.83 & 0.62 & 3.66 & 0.61 & 5.02 & 0.64 & 1.25 & $0.95,1.62$ & 0.10 \\
\hline Legumes† & 0.19 & 0.09 & 0.63 & 0.09 & 0.23 & 0.09 & 0.35 & 0.09 & 1.90 & $1 \cdot 19,3.04$ & $<0.01$ \\
\hline Meat/meat alternatives & $2 \cdot 71$ & 0.19 & 3.43 & 0.20 & 2.95 & 0.20 & $2 \cdot 62$ & 0.20 & 0.81 & $0.34,1.27$ & $<0.001$ \\
\hline Red meat $\dagger$ & 0.64 & 0.13 & 0.85 & 0.13 & 0.78 & $0 \cdot 13$ & 0.71 & $0 \cdot 13$ & 1.09 & $0.95,1.25$ & 0.24 \\
\hline Fresh pork† & 0.09 & 0.05 & 0.44 & 0.06 & $0 \cdot 16$ & 0.05 & 0.13 & 0.05 & $1 \cdot 13$ & $1.06,1.20$ & $<0.001$ \\
\hline Seafood $\dagger$ & 0.38 & 0.08 & 0.64 & 0.08 & 0.30 & 0.08 & 0.39 & 0.08 & 1.19 & $1.05,1.36$ & $<0.01$ \\
\hline Nuts and seeds $\dagger$ & 0.47 & 0.08 & 0.96 & 0.08 & 0.50 & 0.08 & 0.22 & 0.08 & 1.61 & $1.42,1.84$ & $<0.001$ \\
\hline Total dairy products $\dagger$ & 1.80 & 0.20 & 1.60 & 0.20 & 1.92 & 0.20 & 1.93 & 0.20 & 0.85 & $0.64,1 \cdot 11$ & 0.23 \\
\hline EVOO (teaspoons/d)† & 1.14 & 0.39 & 4.51 & 0.39 & $1 \cdot 15$ & 0.39 & 0.68 & 0.39 & $2 \cdot 83$ & $2 \cdot 20,3 \cdot 65$ & $<0.001$ \\
\hline \multicolumn{12}{|l|}{ Serves/d per MJ } \\
\hline Wholegrains & 0.24 & 0.03 & 0.31 & 0.03 & 0.19 & 0.03 & 0.27 & 0.03 & 0.04 & $-0.03,0.12$ & 0.26 \\
\hline Refined grains $†$ & 0.40 & 0.04 & 0.23 & 0.04 & 0.43 & 0.04 & 0.43 & 0.03 & 0.87 & $0.82,0.93$ & $<0.001$ \\
\hline Fruits & 0.15 & 0.02 & 0.28 & 0.02 & 0.18 & 0.02 & 0.24 & 0.02 & 0.04 & $-0.01,0.08$ & 0.13 \\
\hline Vegetables $\dagger$ & 0.49 & 0.06 & 0.71 & 0.06 & 0.43 & 0.06 & 0.58 & 0.07 & 1.21 & $0.94,1.57$ & 0.10 \\
\hline Legumes $†$ & 0.02 & 0.01 & 0.08 & 0.01 & 0.02 & 0.01 & 0.04 & 0.01 & 1.03 & $1.01,1.06$ & $<0.01$ \\
\hline Meat/meat alternatives & 0.30 & 0.02 & 0.42 & 0.02 & 0.33 & 0.02 & 0.34 & 0.02 & 0.08 & $0.03,0.13$ & $<0.01$ \\
\hline Red meat $†$ & 0.08 & 0.02 & $0 \cdot 10$ & 0.02 & 0.08 & 0.02 & 0.09 & 0.02 & 1.01 & $0.98,1.04$ & 0.41 \\
\hline Fresh pork† & 0.01 & 0.01 & 0.06 & 0.01 & 0.02 & 0.01 & 0.02 & 0.01 & 1.04 & $1.02,1.06$ & $<0.001$ \\
\hline Seafood $\dagger$ & 0.04 & 0.01 & 0.08 & 0.01 & 0.04 & 0.01 & 0.04 & 0.01 & 1.03 & $1.01,1.05$ & $<0.01$ \\
\hline Nuts and seeds & 0.05 & 0.01 & $0 \cdot 12$ & 0.01 & 0.06 & 0.01 & 0.03 & 0.01 & 0.09 & $0.06,0.11$ & $<0.001$ \\
\hline Total dairy products & 0.19 & 0.02 & $0 \cdot 19$ & 0.02 & 0.22 & 0.02 & 0.25 & 0.02 & -0.06 & $-0.09,-0.02$ & $<0.01$ \\
\hline EVOO (teaspoons/d per MJ) $\dagger$ & 0.13 & 0.05 & 0.57 & 0.05 & 0.15 & 0.5 & $0 \cdot 10$ & 0.05 & 1.39 & $1.28,1.51$ & $<0.001$ \\
\hline
\end{tabular}

MedPork, Mediterranean diet supplemented with pork; LF, low-fat; vit, vitamin; equiv., equivalents.

* Estimated marginal mean difference from linear mixed-effects models. Differences between interventions were analysed by linear mixed-effects models, including fixed-effect terms for group, visit, group $\times$ visit, period, order and weight (excluding weight-related variables).

† Transformed variable: observed mean and standard error are presented together with rate ratio change in the geometric mean and associated $P$ value.

$\ddagger$ Adjusted for differences between treatments.

Mediterranean dietary pattern for use in Australia. During the MedPork intervention, participants achieved a high level of adherence to MedPork dietary guidelines. The LF intervention led to greater reductions in weight, waist circumference and fat mass. Reductions were observed in morning, afternoon and average SBP following both the MedPork and LF interventions. However, no significant differences were detected between the MedPork and LF interventions for measures of cardiometabolic health, including home and clinic blood pressures, cholesterol, C-reactive protein, insulin and glucose.

Our cardiovascular findings differ from previous studies comparing the Mediterranean diet with the LF diet. A recent meta-analysis reported that Mediterranean diet interventions of at least 1-year duration effectively reduce both SBP and $\mathrm{DBP}^{(34)}$. Notably, pooled analysis across six studies revealed a relatively small effect size. It is possible that the addition of pork 
Table 3. Home blood pressure at baseline and week 8 , including between-group differences

(Mean values with their standard errors; mean differences and $95 \%$ confidence intervals)

\begin{tabular}{|c|c|c|c|c|c|c|c|c|c|c|c|}
\hline & \multicolumn{4}{|c|}{ MedPork diet ( $n$ 33) } & \multicolumn{4}{|c|}{ LF diet $(n 33)$} & \multirow{2}{*}{\multicolumn{2}{|c|}{$\begin{array}{l}\text { Estimated difference } \\
\text { between interventions } \\
(\text { MedPork } v . \text { LF) }\end{array}$}} & \multirow[b]{3}{*}{$P \dagger$} \\
\hline & \multicolumn{2}{|c|}{ Baseline } & \multicolumn{2}{|c|}{ Week 8} & \multicolumn{2}{|c|}{ Baseline } & \multicolumn{2}{|c|}{ Week 8} & & & \\
\hline & Mean & SE & Mean & SE & Mean & SE & Mean & SE & Mean & $95 \% \mathrm{Cl}$ & \\
\hline SBP morning $(\mathrm{mmHg})$ & 126.99 & $1 \cdot 77$ & 126.02 & 1.77 & $125 \cdot 91$ & 1.78 & $124 \cdot 81$ & $1 \cdot 78$ & $1 \cdot 21$ & $-0.12,2.54$ & 0.07 \\
\hline SBP afternoon (mmHg) & 129.62 & 1.66 & $126 \cdot 53$ & 1.66 & 128.06 & 0.67 & $126 \cdot 91$ & 1.66 & -0.38 & $-1.81,1.05$ & 0.60 \\
\hline SBP evening (mmHg) & $126 \cdot 61$ & 1.71 & $127 \cdot 43$ & $1 \cdot 70$ & $127 \cdot 23$ & 1.72 & 127.55 & $1 \cdot 71$ & -0.12 & $-1.54,1.31$ & 0.87 \\
\hline SBP average $(\mathrm{mmHg})$ & $128 \cdot 46$ & 1.59 & $126 \cdot 62$ & 1.58 & $127 \cdot 09$ & 1.59 & $126 \cdot 42$ & 1.59 & 0.20 & $-0.66,1.06$ & 0.64 \\
\hline DBP morning (mmHg) & 76.91 & 1.29 & 77.09 & 1.29 & $77 \cdot 16$ & 1.29 & $77 \cdot 43$ & 1.29 & -0.34 & $-1.23,0.55$ & 0.45 \\
\hline DBP afternoon $(\mathrm{mmHg})$ & $75 \cdot 83$ & $1 \cdot 24$ & $76 \cdot 38$ & $1 \cdot 24$ & $75 \cdot 63$ & $1 \cdot 25$ & $76 \cdot 19$ & $1 \cdot 24$ & $0 \cdot 19$ & $-0.80,1 \cdot 17$ & $0 \cdot 71$ \\
\hline DBP evening (mmHg) & 73.92 & 1.31 & $76 \cdot 24$ & 1.31 & 74.51 & 1.32 & $75 \cdot 76$ & 1.31 & 0.48 & $-0.50,1.46$ & 0.34 \\
\hline DBP average $(\mathrm{mmHg})$ & $75 \cdot 72$ & $1 \cdot 22$ & $76 \cdot 72$ & 1.22 & 75.89 & 1.22 & 76.53 & 0.22 & 0.19 & $-0.39,0.76$ & 0.52 \\
\hline PP morning $(\mathrm{mmHg})$ & $49 \cdot 81$ & 1.58 & $48 \cdot 49$ & 1.57 & 48.57 & 1.58 & $47 \cdot 22$ & 1.58 & $1 \cdot 26$ & $-0.06,2.58$ & 0.06 \\
\hline PP afternoon (mmHg) & 53.73 & 1.54 & $50 \cdot 44$ & 1.54 & 52.49 & 1.55 & $50 \cdot 66$ & 1.54 & -0.22 & $-1 \cdot 56,1 \cdot 12$ & 0.75 \\
\hline PP evening (mmHg) & $54 \cdot 89$ & 1.55 & 51.43 & 1.55 & $52 \cdot 74$ & 1.56 & 51.79 & 1.56 & -0.36 & $-1.65,0.93$ & 0.59 \\
\hline PP average $(\mathrm{mmHg})$ & $52 \cdot 84$ & 1.48 & $50 \cdot 05$ & 1.47 & $51 \cdot 25$ & 1.48 & $49 \cdot 88$ & 1.48 & 0.17 & $-0.63,0.97$ & 0.68 \\
\hline HR morning (bpm) & 67.55 & 1.27 & 66.66 & $1 \cdot 27$ & $66 \cdot 22$ & 1.27 & 66.57 & 1.27 & $0 \cdot 10$ & $-0.73,0.92$ & 0.81 \\
\hline HR afternoon (bpm) & 71.65 & 1.26 & 70.95 & 1.26 & 71.33 & 1.27 & $70 \cdot 73$ & 1.26 & 0.21 & $-0.86,1 \cdot 28$ & $0 \cdot 70$ \\
\hline HR evening (bpm) & 73.01 & 1.14 & $70 \cdot 56$ & 1.14 & $70 \cdot 27$ & $1 \cdot 15$ & $70 \cdot 05$ & 1.14 & 0.51 & $-0.51,1.52$ & 0.32 \\
\hline HR average (bpm) & $70 \cdot 25$ & 1.51 & $69 \cdot 20$ & 0.51 & $68 \cdot 81$ & 0.51 & 69.03 & 1.51 & 0.17 & $-0.45,0.79$ & 0.60 \\
\hline
\end{tabular}

MedPork, Mediterranean diet supplemented with pork; LF, low-fat; SBP, systolic blood pressure; DBP, diastolic blood pressure; PP, pulse pressure; HR, heart rate; bpm, beats per min. * Estimated marginal mean difference from linear mixed-effects models. Differences between interventions were analysed by linear mixed-effects models, including fixed-effect terms for group, visit, group $\times$ visit, period, order and weight.

† Adjusted for differences between treatments.

Table 4. Clinic measures at baseline and week 8 , including between-group differences

(Mean values with their standard errors; mean differences and $95 \%$ confidence intervals)

\begin{tabular}{|c|c|c|c|c|c|c|c|c|c|c|c|}
\hline & \multicolumn{4}{|c|}{ MedPork diet (n 33) } & \multicolumn{4}{|c|}{ LF diet ( $n$ 33) } & \multirow{2}{*}{\multicolumn{2}{|c|}{$\begin{array}{l}\text { Estimated difference } \\
\text { between interventions } \\
(\text { MedPork } v . \text { LF)* }\end{array}$}} & \multirow[b]{3}{*}{$P \ddagger$} \\
\hline & \multicolumn{2}{|c|}{ Baseline } & \multicolumn{2}{|c|}{ Week 8} & \multicolumn{2}{|c|}{ Baseline } & \multicolumn{2}{|c|}{ Week 8} & & & \\
\hline & Mean & SE & Mean & SE & Mean & SE & Mean & SE & Mean & $95 \% \mathrm{Cl}$ & \\
\hline SBP clinic $(\mathrm{mmHg})$ & $134 \cdot 81$ & 2.60 & $129 \cdot 75$ & 2.62 & $128 \cdot 45$ & 2.64 & $127 \cdot 22$ & 2.64 & 2.53 & $-1.63,6.68$ & 0.23 \\
\hline DBP clinic $(\mathrm{mmHg})$ & 84.91 & 1.57 & $83 \cdot 23$ & 1.58 & 84.04 & 1.59 & 83.77 & 1.59 & -0.53 & $-2.90,1.84$ & 0.66 \\
\hline HR clinic (bpm) & 65.92 & 1.44 & 65.57 & 1.45 & $67 \cdot 12$ & 1.47 & 64.86 & 1.47 & 0.71 & $-1.89,3.32$ & 0.59 \\
\hline Insulin (mU/l)† & $10 \cdot 66$ & 0.90 & $12 \cdot 07$ & 0.90 & $10 \cdot 74$ & 0.92 & 10.56 & 0.91 & 1.07 & $0.95,1.20$ & 0.26 \\
\hline Glucose (mmol/l) & $5 \cdot 26$ & 0.12 & $5 \cdot 28$ & 0.12 & $5 \cdot 32$ & 0.12 & $5 \cdot 21$ & 0.12 & 0.01 & $-0.09,0.11$ & 0.38 \\
\hline $\mathrm{CRP}(\mathrm{mg} / \mathrm{l}) \dagger$ & 1.99 & 0.33 & 2.09 & 0.33 & $2 \cdot 26$ & 0.34 & $2 \cdot 11$ & 0.34 & 1.03 & $0.82,1.30$ & 0.79 \\
\hline Total TAG $(\mathrm{mmol} / \mathrm{l}) \dagger$ & 1.51 & 0.11 & 1.50 & 0.11 & 1.49 & 0.11 & 1.54 & 0.11 & 0.94 & $0.86,1.04$ & 0.22 \\
\hline Total chol $(\mathrm{mmol} / \mathrm{l})$ & $5 \cdot 74$ & 1.44 & 5.42 & 1.45 & $5 \cdot 71$ & 1.45 & 5.49 & 1.45 & -0.07 & $-0.26,0.12$ & 0.47 \\
\hline $\mathrm{HDL}(\mathrm{mmol} / \mathrm{l})$ & 1.56 & 0.06 & 1.47 & 0.06 & 1.55 & 0.06 & 1.47 & 0.06 & 0.01 & $-0.06,0.07$ & 0.87 \\
\hline LDL (mmol/l) & 3.46 & 0.13 & $3 \cdot 24$ & 0.13 & 3.45 & 0.13 & $3 \cdot 32$ & 0.13 & -0.07 & $-0.23,0.08$ & 0.36 \\
\hline Chol:HDL ratio† & 3.83 & 0.16 & 3.81 & 0.16 & 3.84 & 0.16 & 3.87 & 0.16 & 1.00 & $0.96,1.04$ & 0.85 \\
\hline Weight (kg) & $84 \cdot 33$ & 2.91 & 83.08 & $2 \cdot 91$ & $84 \cdot 26$ & $2 \cdot 91$ & 82.43 & 2.91 & 0.65 & $0.04,1.25$ & 0.04 \\
\hline BMI $\left(\mathrm{kg} / \mathrm{m}^{2}\right) \dagger$ & $30 \cdot 40$ & 0.84 & 29.94 & 0.84 & $30 \cdot 35$ & 0.84 & 29.69 & 0.84 & 1.02 & $1.00,1.02$ & 0.01 \\
\hline Waist circumference $(\mathrm{cm})$ & 99.51 & $2 \cdot 15$ & $98 \cdot 73$ & $2 \cdot 15$ & 99.53 & $2 \cdot 15$ & $97 \cdot 33$ & $2 \cdot 15$ & 1.40 & $0.45,2.34$ & $<0.01$ \\
\hline Hip circumference $(\mathrm{cm})$ & $109 \cdot 61$ & 2.06 & $108 \cdot 17$ & 2.06 & $109 \cdot 76$ & 2.06 & $108 \cdot 12$ & 2.06 & 0.05 & $-0.72,0.81$ & 0.90 \\
\hline Fat mass (\%) & $42 \cdot 11$ & 1.48 & 41.69 & 1.47 & 43.02 & 1.48 & 41.35 & 1.48 & 0.34 & $-0.70,1.37$ & 0.52 \\
\hline Lean mass (\%) & 55.99 & $1 \cdot 36$ & $56 \cdot 37$ & $1 \cdot .36$ & $55 \cdot 88$ & 1.36 & $56 \cdot 81$ & $1 \cdot 36$ & -0.44 & $-0.92,0.05$ & 0.08 \\
\hline Fat mass $(\mathrm{kg}) \dagger$ & $34 \cdot 88$ & 1.92 & 34.04 & 1.92 & 34.92 & 1.92 & 33.46 & 1.92 & 1.02 & $1.00,1.04$ & 0.04 \\
\hline Lean mass $(\mathrm{kg}) \dagger$ & $47 \cdot 21$ & 1.85 & $46 \cdot 81$ & 1.85 & $47 \cdot 13$ & 1.85 & $46 \cdot 81$ & 1.85 & 1.01 & $0.96,1.01$ & 0.29 \\
\hline Abdominal fat (kg) & 3.40 & 0.21 & 3.29 & 0.21 & 3.39 & 0.22 & $3 \cdot 28$ & 0.22 & 0.01 & $-0.11,0.13$ & 0.87 \\
\hline
\end{tabular}

MedPork, Mediterranean diet supplemented with pork; LF, low-fat, SBP, systolic blood pressure; DBP, diastolic blood pressure; HR, heart rate; CRP, C-reactive protein;

chol, cholesterol.

* Estimated marginal mean difference from linear mixed-effects models. Differences between interventions were analysed by linear mixed-effects models, including fixed-effect terms for group, visit, group $\times$ visit, period, order and weight (excluding weight-related variables).

$\dagger$ Transformed variable: observed mean and standard error are presented together with rate ratio change in the geometric mean and associated $P$ value.

$\ddagger$ Adjusted for differences between treatments.

to the Mediterranean diet displaced other bioactive ingredients and diluted these effects. Alternatively, the 8-week MedPork intervention may not have been long enough to elicit significant changes in blood pressure. Similarly, an 8-week intervention may have limited our capacity to observe significant improvements in secondary markers of cardiometabolic health, such as cholesterol, glucose and insulin, as seen in longer intervention trials $^{(3)}$. 
Table 5. Subgroup analysis: average systolic blood pressure (SBP), diastolic blood pressure (DBP) and pulse pressure at baseline and week 8 , including between-group differences, in overweight $\left(B M I<30 \mathrm{~kg} / \mathrm{m}^{2}\right)$ and obese $\left(\mathrm{BMI} \geq 30 \mathrm{~kg} / \mathrm{m}^{2}\right)$ participants

(Mean values with their standard errors; mean differences and $95 \%$ confidence intervals)

\begin{tabular}{|c|c|c|c|c|c|c|c|c|c|c|c|}
\hline & \multicolumn{4}{|c|}{ MedPork diet } & \multicolumn{4}{|c|}{ LF diet } & \multirow{2}{*}{\multicolumn{2}{|c|}{$\begin{array}{l}\text { Estimated difference } \\
\text { between interventions } \\
(\text { MedPork } v . \text { LF) }\end{array}$}} & \multirow[b]{3}{*}{$P+$} \\
\hline & \multicolumn{2}{|c|}{ Baseline } & \multicolumn{2}{|c|}{ Week 8} & \multicolumn{2}{|c|}{ Baseline } & \multicolumn{2}{|c|}{ Week 8} & & & \\
\hline & Mean & SE & Mean & SE & Mean & SE & Mean & SE & Mean & $95 \% \mathrm{Cl}$ & \\
\hline \multicolumn{12}{|l|}{ SBP average } \\
\hline Overweight ( $n 17)$ & $127 \cdot 51$ & 1.87 & 124.39 & 1.86 & $126 \cdot 37$ & 1.88 & 125.95 & 1.88 & -1.56 & $-2.77,-0.34$ & 0.01 \\
\hline Obese $(n 14)$ & $132 \cdot 71$ & $2 \cdot 40$ & $132 \cdot 22$ & $2 \cdot 38$ & 131.35 & $2 \cdot 38$ & $128 \cdot 54$ & $2 \cdot 36$ & $2 \cdot 68$ & $1 \cdot 25,4 \cdot 10$ & $<0.001$ \\
\hline \multicolumn{12}{|l|}{ DBP average } \\
\hline Overweight ( $n$ 17) & 73.49 & 1.36 & $75 \cdot 24$ & 1.36 & 73.82 & 1.37 & 74.02 & 1.36 & $1 \cdot 22$ & $0.45,1.98$ & $<0.01$ \\
\hline Obese $(n 14)$ & $80 \cdot 50$ & 2.04 & $80 \cdot 67$ & 2.02 & $80 \cdot 35$ & 2.04 & 81.59 & 2.03 & -0.92 & $-1.87,0.03$ & 0.06 \\
\hline \multicolumn{12}{|c|}{ Pulse pressure average } \\
\hline Overweight ( $n$ 17) & $57 \cdot 71$ & 2.81 & 50.75 & 2.81 & 54.68 & 2.89 & 52.96 & 2.89 & $-2 \cdot 21$ & $-3.55,-0.88$ & $<0.01$ \\
\hline Obese $(n 14)$ & 53.66 & $2 \cdot 64$ & 53.63 & 2.56 & $52 \cdot 84$ & 2.59 & $48 \cdot 28$ & 2.55 & $5 \cdot 36$ & $3.71,7 \cdot 00$ & $<0.001$ \\
\hline
\end{tabular}

MedPork, Mediterranean diet supplemented with pork; LF, low-fat.

* Estimated marginal mean difference from linear mixed-effects models. Differences between interventions were analysed by linear mixed-effects models, including fixed-effect terms for group, visit, group $\times$ visit, period, order and weight.

† Adjusted for differences between treatments.

The comparable changes in blood pressure may be partly explained by improvements to overall diet quality. Both the MedPork and LF intervention led to increased consumption of wholegrains, vegetables, fruit and fibre, and reduced intake of saturated fat. Notably, recent systematic reviews have reported that replacing SFA with MUFA, PUFA or high-quality carbohydrates has similarly beneficial effects on blood pressure and risk of cardiovascular events ${ }^{(35,36)}$. The LF intervention also led to significant improvements in measures of body composition. This is likely due to significant reductions in fat intake. However, reductions in weight, BMI, waist circumference and fat mass did not translate to improvements across other markers of cardiovascular health. While changes may have been observed over a longer intervention, previous research, including the PREDIMED trial, indicates that the LF diet is unsustainable and difficult to follow over extended periods of time ${ }^{(27)}$.

Our sub-group analyses revealed a significant effect of the MedPork intervention for average home SBP in overweight participants. In contrast, the LF intervention led to a decrease in average home SBP in obese participants. Corresponding with these reductions in SBP were increased DBP: the MedPork intervention led to an increase in DBP in the overweight group, while the LF intervention led to an increased DBP in the obese group. By reducing the difference between SBP and DBP, the MedPork diet led to significant improvements in pulse pressure for overweight participants. Likewise, the LF intervention led to significant improvements in pulse pressure for obese participants. These findings indicate that the MedPork intervention may improve vascular haemodynamics in overweight individuals, while obese individuals may require further dietetic intervention, such as energy restriction with targeted weight loss, to achieve similar results. However, these findings should be interpreted with caution due to the small sample size of overweight and obese individuals included in the analysis.

It is important to acknowledge the following limitations. As mentioned above, the present study was limited in duration, comparing two 8-week interventions. Although similar nutritional interventions have elicited cardiovascular change over comparable time periods, a longer intervention may have led to stronger results. Our selection criteria were developed to identify individuals at risk of CVD. This included individuals with a minimum SBP of $120 \mathrm{mmHg}$. However, higher blood pressure values may have been more responsive to our intervention. It is also important to note modifications made to the Mediterranean diet, which may have influenced our results. Firstly, the addition of pork increased red meat consumption. Although the change was not significant, higher red meat intake is not characteristic of a traditional Mediterranean diet ${ }^{(1)}$. Fresh lean pork was included to assist with compliance and to provide an alternative meat source to beef, Australia's main source of red meat. This choice was also supported by a study conducted by our research group, which found that replacing chicken with pork has positive cardiometabolic outcomes ${ }^{(19)}$. Notwithstanding, the MedPork intervention aimed to reduce total meat intake and promote consumption of meat alternatives. In Australia, average meat consumption is $800 \mathrm{~g} /$ week $^{(12)}$. During the MedPork intervention, participants were advised to consume no more than $400 \mathrm{~g} /$ week. Participants were also monitored to ensure they consistently consumed legumes, seafood, and nuts and seeds, along with other traditional components of the diet. The present study also modified EVOO recommendations to suit an Australian population. Although our guidelines were lower than traditional values, participants increased their EVOO consumption (teaspoons/MJ) 5-fold between baseline and week 8 . Consistent with the adoption of Mediterranean dietary principles, participants significantly increased MUFA intake and improved MUFA:SFA ratio. Further, at week 8 of the MedPork intervention, macronutrient ratios were consistent with that of a Mediterranean diet (approximately $40 \%$ energy from fat, approximately $40 \%$ energy from carbohydrates and approximately $20 \%$ energy from protein). The shift in dietary intake was captured by the MDS and MedPork adherence score. Interestingly, the MDS increased by 2 points between baseline and week 8, while the MedPork adherence score increased by 7.5 points. This difference is probably due to the information captured by each score: the MDS is based on actual dietary 
intake, measured in grams, while the MedPork adherence score assesses overall adherence to dietary principles. Further, the MDS penalises meat consumption, while the MedPork adherence score was tailored to accommodate the inclusion of pork.

With regard to study design, the provision of study foods during the MedPork intervention probably contributed to the level of adherence to the intervention and may limit generalisability. The design of the LF intervention may not reflect current LF dietary recommendations in Australia. Since the study's conceptions, dietary guidelines for heart health have been updated and now include advice to consume healthy fats from nuts, seeds, fish and olive oil ${ }^{(37)}$. In light of these limitations, future investigations should consider clinical populations, higher consumption of EVOO, longer time periods, feasibility of adherence without the provision of food supplies and a control that is reflective of current dietary habits in Australia.

To reduce the burden of CVD, health and lifestyle interventions with the potential to mitigate multiple risk factors have been recommended above reactive, costly treatments ${ }^{(38,39)}$. Interventions like the Mediterranean diet may be effective in reducing incidence and prevalence of CVD. However, it is necessary to ensure that such interventions are suitable for the target population. The present study employed a rigorous design to evaluate the cardiovascular effects of a modified Mediterranean diet developed for an Australian population.

Both the MedPork and LF interventions led to similar improvements across blood pressure measures. This indicates that the MedPork intervention has a similar cardiovascular risk profile to an LF diet and can be adhered to by an Australian population at risk of CVD. These findings are relevant at both an individual and policy level and provide insight regarding future dietary recommendations for individuals in the general community. Longer intervention trials with larger sample sizes are now required to demonstrate the longer-term feasibility and clinical effectiveness of the MedPork intervention in a population with elevated blood pressure.

\section{Acknowledgements}

The authors would like to thank Louise Massie for clinical trials support. We would also like to acknowledge the following organisations for their generous contributions: Almond Board of Australia for the donation of almonds; Cobram Estate for the donation of Australian EVOO; and Simplot Australia Pty Ltd for the donation of legumes, tuna and salmon.

The present study was funded by the Pork Cooperative Research Centre (no. 3B-113). The Pork CRC had no role in the study design, implementation, analysis or interpretation of data. A. T. W. was supported by an Australian Government Research Training Program (RTP) Scholarship. J. M. H. was supported by a National Health and Medical Research Council Senior Research Fellowship and a Royal Perth Hospital Medical Research Foundation Fellowship.

K. J. M., J. M. H., A. T. W. and C. R. D. designed the project. K. J. M. and C. R. D. developed the dietary interventions. K. J. M., A. T. W., J. M. H. and C. R. D. developed the cardiovascular measures. R. J. W. contributed to the study design and developed the statistical approach. K. A. D. contributed to the study design. K. J. M., A. T. W., K. A. D. and C. R. D. conducted the trial and collected study data. A. T. W. prepared the manuscript. All authors reviewed manuscript drafts and approved the final version.

None of the authors has any conflicts of interest to declare.

\section{Supplementary material}

For supplementary material/s referred to in this article, please visit https://doi.org/10.1017/S0007114519001168

\section{References}

1. Davis CR, Bryan J, Hodgson J, et al. (2015) Definition of the Mediterranean diet: a literature review. Nutrients 7, 9139-9153.

2. Sofi F, Macchi C, Abbate R, et al. (2014) Mediterranean diet and health status: an updated meta-analysis and a proposal for a literature-based adherence score. Public Health Nutr 17, 2769-2782.

3. Martínez-González MA, Salas-Salvadó J, Estruch R, et al. (2015) Benefits of the Mediterranean diet: insights from the PREDIMED study. Prog Cardiovasc Dis 58, 50-60.

4. Davis CR, Hodgson JM, Woodman R, et al. (2017) A Mediterranean diet lowers blood pressure and improves endothelial function: results from the MedLey randomized intervention trial. Am J Clin Nutr 105, 1305-1313.

5. Wade AT, Davis CR, Dyer KA, et al. (2018) A Mediterranean diet supplemented with dairy foods improves markers of cardiovascular risk in an Australian population. Am J Clin Nutr 108, 1166-1182.

6. Lee J, Pase M, Pipingas A, et al. (2015) Switching to a 10-day Mediterranean-style diet improves mood and cardiovascular function in a controlled crossover study. Nutrition 31, 647-652.

7. Nutrition Australia (2015) Healthy Eating Pyramid. Victoria: Australian Nutrition Foundation.

8. Davis CR, Bryan J, Hodgson JM, et al. (2015) A randomised controlled intervention trial evaluating the efficacy of a Mediterranean dietary pattern on cognitive function and psychological wellbeing in healthy older adults: the MedLey study. BMC Geriatr 15, 55.

9. Davis CR, Hodgson J, Bryan J, et al. (2017) Older Australians can achieve high adherence to the Mediterranean diet during a 6 month intervention; results from the Medley study. Nutrients 9, 534 .

10. Ministry of Health and Welfare and Supreme Scientific Health Council (1999) Dietary guidelines for adults in Greece. Arch Hell Med 16, 516-524.

11. Bach-Faig A, Berry EM, Lairon D, et al. (2011) Mediterranean diet pyramid today. Science and cultural updates. Public Health Nutr 14, 2274-2284.

12. Australian Bureau of Statistics (2016) Australian Health Survey: consumption of Food Groups from the Australian Dietary Guidelines, 2011-12. Australia: ACT.

13. Organisation for Economic Cooperation and Development (2016) Agricultural Output: Meat Consumption. Organisation for Economic Cooperation and Development (OECD). https://data.oecd.org/agroutput/meat-consumption.htm

14. Knight A, Bryan J \& Murphy K (2016) Is the Mediterranean diet a feasible approach to preserving cognitive function and reducing risk of dementia for older adults in Western countries? New insights and future directions. Ageing Res Rev 25, 85-101.

15. Wolk A (2017) Potential health hazards of eating red meat. J Intern Med 281, 106-122. 
16. Van Hecke $\mathrm{T}$, Van Camp J \& De Smet S (2017) Oxidation during digestion of meat: interactions with the diet and Helicobacter pylori gastritis, and implications on human health. Compr Rev Food Sci Food Saf 16, 214-233.

17. Tirosh O, Shpaizer A \& Kanner J (2015) Lipid peroxidation in a stomach medium is affected by dietary oils (olive/fish) and antioxidants: the Mediterranean versus Western diet. J Agric Food Chem 63, 7016-7063.

18. Norat T, Bingham S, Ferrari P, et al. (2005) Meat, fish, and colorectal cancer risk: the European Prospective Investigation into Cancer and Nutrition. JNCI J Natl Cancer Inst 97, 906-916.

19. Murphy KJ, Thomson RL, Coates AM, et al. (2012) Effects of eating fresh lean pork on cardiometabolic health parameters. Nutrients 4, 711-723.

20. Tilman D \& Clark M (2014) Global diets link environmental sustainability and human health. Nature $\mathbf{5 1 5}, 518-522$.

21. National Vascular Disease Prevention Alliance (2012) Guidelines for the Management of Absolute Cardiovascular Disease Risk. Canberra: National Health and Medical Research Council.

22. Estruch R, Ros E, Salas-Salvadó J, et al. (2013) Primary prevention of cardiovascular disease with a Mediterranean diet. NEngl J Med 368, 1279-1290.

23. Wade AT, Davis CR, Dyer KA, et al. (2017) Including pork in the Mediterranean diet for an Australian population: protocol for a randomised controlled trial assessing cardiovascular risk and cognitive function. Nutr J 16, 84 .

24. Desideri G, Kwik-Uribe C, Grassi D, et al. (2012) Benefits in cognitive function, blood pressure, and insulin resistance through cocoa flavanol consumption in elderly subjects with mild cognitive impairment: the Cocoa, Cognition, and Aging (CoCoA) study. Hypertension 60, 794-801.

25. Mastroiacovo D, Kwik-Uribe C, Grassi D, et al. (2015) Cocoa flavanol consumption improves cognitive function, blood pressure control, and metabolic profile in elderly subjects: the Cocoa, Cognition, and Aging (CoCoA) study - a randomized controlled trial. Am J Clin Nutr 101, 538-548.

26. Nilsson A, Radeborg K, Salo I, et al. (2012) Effects of supplementation with $n-3$ polyunsaturated fatty acids on cognitive performance and cardiometabolic risk markers in healthy 51 to 72 years old subjects: a randomized controlled cross-over study. Nutr J 11, 99.
27. Martínez-González MA, Corella D, Salas-Salvadó J, et al. (2012) Cohort profile: design and methods of the PREDIMED study. Int J Epidemiol 41, 377-385.

28. National Health and Medical Research Council (2013) Australian Dietary Guidelines. Canberra: NHMRC.

29. National Heart Foundation of Australia and Cardiac Society of Australia and New Zealand (2012) Reducing Risk in Heart Disease: an Expert Guide to Clinical Practice for Secondary Prevention of Coronary Heart Disease. Melbourne, Australia: NHF.

30. The Australian National Health and Medical Research Council (2009) Australian Guidelines to Reduce Health Risks from Drinking Alcobol. Canberra: The Australian National Health and Medical Research Council.

31. Trichopoulou A, Costacou T, Bamia C, et al. (2003) Adherence to a Mediterranean diet and survival in a Greek population. $N$ Engl J Med 348, 2599-2608.

32. Hsieh FY, Lavori PW, Cohen HJ, et al. (2003) An overview of variance inflation factors for sample-size calculation. Eval Health Prof 26, 239-257.

33. Dong Y, Ma J, Song Y, et al. (2018) Secular trends in blood pressure and overweight and obesity in Chinese boys and girls aged 7 to 17 years from 1995 to 2014. Hypertension 72, 298-305.

34. Nissensohn M, Román-Viñas B, Sánchez-Villegas A, et al. (2016) The effect of the Mediterranean diet on hypertension: a systematic review and meta-analysis. J Nutr Educ Behav 48, 42-53.e1.

35. Clifton PM \& Keogh JB (2017) A systematic review of the effect of dietary saturated and polyunsaturated fat on heart disease. Nutr Metab Cardiovasc Dis 27, 1060-1080.

36. Jovanovski E, de Castro Ruiz Marques A, Li D, et al. (2019) Effect of high-carbohydrate or high-monounsaturated fatty acid diets on blood pressure: a systematic review and meta-analysis of randomized controlled trials. Nutr Rev 77, 19-31.

37. National Heart Foundation of Australia (2017) Dietary Fat and Heart Healthy Eating: Position Statement. Canberra, Australia: National Heart Foundation.

38. Mendis S, Puska P \& Norrving B (2011) Global Atlas on Cardiovascular Disease Prevention and Control. Geneva: World Health Organization.

39. Norton S, Matthews FE, Barnes DE, et al. (2014) Potential for primary prevention of Alzheimer's disease: an analysis of population-based data. Lancet Neurol 13, 788-794. 